\title{
RETRACTED ARTICLE: Measuring the systemic importance of Chinese banks based on risk interactions
}

\author{
Abdelkader Derbali ${ }^{1,2} \cdot$ Lamia Jamel $^{3} \cdot$ Shan $\mathrm{Wu}^{4}$
}

Received: 20 June 2019 / Accepted: 7 February 2020 / Published online: 31 July 2020

(c) Springer-Verlag GmbH Germany, part of Springer Nature 2020

The Editor-in-Chief has retracted this article [1] because it has been previously published by another a group [2]. All authors agree with this retraction. The online version of this article contains the full text of the retracted article as electronic supplementary material.

[1] Derbali A, Jamel L, Wu S (2020) Measuring the systemic importance of Chinese banks based on risk interactions. Empir Econ. https://doi.org/10.1007/s00181-020-01 $834-2$

[2] Bao C, Wu D, Li J (2020) Measuring systemic importance of banks considering risk interactions: An ANOVA-like decomposition method. J Manag Sci Eng 5(1):23-42

Publisher's Note Springer Nature remains neutral with regard to jurisdictional claims in published maps and institutional affiliations.

\section{Affiliations}

\section{Abdelkader Derbali ${ }^{1,2} \cdot$ Lamia Jamel $^{3} \cdot$ Shan $\mathrm{Wu}^{4}$}

$凶$ Abdelkader Derbali

derbaliabdelkader@outlook.fr

Lamia Jamel

lajamel@yahoo.fr

Shan $\mathrm{Wu}$

wushaniam@outlook.com

1 Department of Administrative and Financial Sciences and Techniques, Community College, Taibah University, Medinah, Saudi Arabia

Electronic supplementary material The online version of this article (https://doi.org/10.1007/s00181-02 0-01834-2) contains supplementary material, which is available to authorized users.

Extended author information available on the last page of the article 
2 Department of Management Sciences, Higher Institute of Informatics and Management of Kairouan, Kairouan University, Kairouan, Tunisia

3 Department of Finance and Economic, College of Business Administration, Taibah University, Medinah, Saudi Arabia

4 School of Finance, Nanjing University of Finance and Economics, Jiangsu, China 